\title{
New method for an occupational dust challenge
}

test

Fung J Lin, Henry Chen, Moira Chan-Yeung

\begin{abstract}
Objectives-Specific challenge tests with a suspected allergen in the workplace are standard to confirm the diagnosis of asthma. Facilities for sophisticated exposure tests are available only in a few institutions. A pilot study was carried out that used a novel approach for an occupational dust challenge test with a rotahaler.
\end{abstract}

Methods-Nine consecutive patients were enrolled in this study. Six of these proved to have asthma to red cedar by challenge tests with plicatic acid. They were challenged with a maximum dosage of $80 \mathrm{mg}$ of red cedar dust and spruce dust (control) with a rotahaler on separate days in a single blinded manner. A positive reaction was defined as a fall in the forced expiratory volume in one second (FEV $)$ or the peak expiratory flow (PEF) after a challenge test of $\geqslant 20 \%$ below the baseline value.

Results-Three of the six patients who reacted to plicatic acid also had a positive response to red cedar dust delivered through a rotahaler. All three patients with a negative response to challenge with plicatic acid also showed a negative response to red cedar dust.

Conclusions-This pilot study showed that a positive challenge test with a rotahaler to deliver red cedar dust was specific in the diagnosis of red cedar asthma but a negative response could not rule out the diagnosis. The rotahaler has merits of being easy to operate, safe, inexpensive, and readily available. The usefulness of this method and its reproducibility have to be examined in a series of patients.

(Occup Environ Med 1995;52:54-56)

Respiratory Division, Department of Medicine, Vancouver General Hospital, University of British Columbia, Canada H Chen

M Chan-Yeung

Respiratory Division, Department of

Medicine, MacKay Memorial Hospital, Taiwan

F J Lin

Correspondence to: Dr Fung J Lin, Respiratory Division, MacKay Memorial Hospital, 92 Section 2, Chung-San North Road Taipei, Taiwan 10449 Republic of China.

Accepted 15 September 1994

Keywords: occupational asthma; rotahaler; diagnosis; dust challenge

Occupational asthma has become the most common form of occupational lung disease in developed countries. ${ }^{12}$ The diagnosis of occupational asthma has considerable impact on the patient particularly from the socioeconomic point of view. ${ }^{3}$ It is important that the diagnosis be accurate and confirmed by an objective method. offending agent from the workplace has been considered to be the gold standard test to confirm the diagnosis of occupational asthma. Unfortunately specific inhalation tests with done in few institutions where facilities and expertise are available. The diagnosis of red cedar asthma can be confirmed by an inhalation test with plicatic acid, which has been found to be responsible for red cedar asthma. ${ }^{5}$ Moreover, it is quite possible that other chemicals in this wood dust may also be capable of causing red cedar asthma. ${ }^{6}$ Exposure to wood dusts, including red cedar dust, has been used to confirm work related asthma by many investigators. ${ }^{7}$ It is a more natural way of exposure and is particularly useful when the agent in the dust responsible for asthma is not known. Moreover, wood dusts are readily available.

This is a report of the results of a pilot study with a rotahaler device to deliver fine cedar dust as a challenge test. The purpose of the study was to examine whether this method can replace the use of plicatic acid, which is not commercially available, in challenge tests to confirm the diagnosis of red cedar asthma.

\section{Materials and methods}

SUBJECTS AND STUDY PROTOCOL

Nine patients, who were consecutively referred for suspected red cedar asthma to the Respiratory Clinic of the University of British Columbia between October 1992 and February 1993, were included in this study. Challenge tests with wood dust were carried out in a single blind manner on two separate days, one to two weeks apart, when a repeat challenge test with methacholine showed less than a twofold change from the previous determination and the diurnal variation in peak expiratory flow (PEF) was $<10 \%$. Patients who took $\beta$ agonists were told to withhold the medication for six hours before challenge tests. Those who took inhaled steroids were asked to use the medication regularly in the same manner for the whole duration of the study.

A specific challenge test with the suspected sophisticated exposure methods ${ }^{4}$ can only be

\section{PULMONARY FUNCTION TESTS}

Spirometry was done with an Ohio 840 dry spirometer (Airco, Ohio Medical Product, Houston, Texas, USA). Peak expiratory flow was measured by a Wright Peak Flow MiniMeter (Airmed, Clement Clark International, England). Predictive values for forced expiratory volume in one second $\left(F E V_{1}\right)$ and forced vital capacity (FVC) were calculated from the regression model of Crapo et al. ${ }^{8}$

\section{CHALLENGE TEST WITH METHACHOLINE}

Challenge tests with methacholine were carried out according to the method described by Cockcroft et al. ${ }^{9}$ Methacholine solutions from 0.03 to $32.0 \mathrm{mg} / \mathrm{ml}$ were inhaled at tidal 
Table 1 Characteristics of patients and their response to inhalation test

\begin{tabular}{|c|c|c|c|c|c|c|c|c|c|}
\hline \multirow{2}{*}{$\begin{array}{l}\text { Subject } \\
\text { No }\end{array}$} & \multirow{2}{*}{$\begin{array}{l}\text { Age } \\
(y)\end{array}$} & \multirow[b]{2}{*}{ Atopy } & \multirow{2}{*}{$\begin{array}{l}F E V_{1} \\
\% \text { predicted }\end{array}$} & \multirow{2}{*}{$\begin{array}{l}F V C \\
\% \text { predicted }\end{array}$} & \multicolumn{2}{|c|}{ Challenge with plicatic acid } & \multicolumn{3}{|c|}{ Challenge with cedar dust } \\
\hline & & & & & $P C_{20}$ & Response & $P C_{20}$ & Response & Dose $(m g)$ \\
\hline $\begin{array}{l}1 \\
2 \\
3 \\
4 \\
4 \\
5 \\
6 \\
7 \\
8 \\
8 \\
9\end{array}$ & $\begin{array}{l}24 \\
29 \\
35 \\
33 \\
44 \\
51 \\
28 \\
42 \\
60\end{array}$ & $\begin{array}{l}- \\
+ \\
- \\
+ \\
- \\
+ \\
+ \\
- \\
-\end{array}$ & $\begin{array}{r}86 \\
111 \\
91 \\
101 \\
86 \\
72 \\
99 \\
64 \\
75\end{array}$ & $\begin{array}{r}84 \\
109 \\
118 \\
106 \\
96 \\
74 \\
106 \\
88 \\
84\end{array}$ & $\begin{array}{c}>32 \\
9.70 \\
1.83 \\
15.2 \\
5.79 \\
1.45 \\
1.16 \\
0.95 \\
>32\end{array}$ & $\begin{array}{l}- \\
- \\
\overline{\text { LAR }} \\
\text { LAR } \\
\text { DAR } \\
\text { IAR } \\
\text { LAR } \\
\text { LAR }\end{array}$ & $\begin{array}{c}>32 \\
11.89 \\
2.0 \\
3.64 \\
7.27 \\
0.87 \\
1.82 \\
1.07 \\
>32\end{array}$ & $\begin{array}{l}- \\
- \\
- \\
- \\
- \\
- \\
\text { IAR } \\
\text { LAR } \\
\text { LAR }\end{array}$ & $\begin{array}{l}40 \\
80 \\
80 \\
80 \\
80 \\
80 \\
20 \\
80 \\
80\end{array}$ \\
\hline
\end{tabular}

$\mathrm{LAR}=$ isolated late asthmatic reaction; $\mathrm{LAR}=$ isolated immediate asthmatic reaction; $\mathrm{DAR}=$ dual asthmatic reaction

breathing for two minutes through a BennettTwin nebuliser. The concentration of methacholine that induced a drop of $20 \%$ of $\mathrm{FEV}_{1}$ from the lowest value after saline was determined by interpolation of a non-cumulative dose-response curve $\left(\mathrm{PC}_{20}\right)$.

SPECIFIC CHALLENGE TEST WITH PLICATIC ACID The method used for the specific challenge test with plicatic acid was described previously. ${ }^{10}$ Plicatic acid was supplied by Forintek, Vancouver, Canada. Plicatic acid of 0.625 $\mathrm{mg} / \mathrm{ml}$ was given by inhalation through a Bennett-Twin nebuliser for two minutes at tidal breathing. This was followed by measurement of $\mathrm{FEV}_{1}$ at 30 seconds and 10 minutes. The inhalation of plicatic acid was repeated with twofold concentrations until a concentration of $10 \mathrm{mg} / \mathrm{ml}$ was given or when a drop in $\mathrm{FEV}_{1}$ of $20 \%$ from the value after saline was reached (positive immediate reaction). After the last inhalation of plicatic acid, $\mathrm{FEV}_{1}$ was measured at 10 minute intervals during the first hour and hourly for six hours. The patient continued to measure PEF hourly up to bedtime and at night, if awakened by dyspnoea. A positive late reaction was defined as a fall in $\mathrm{FEV}_{1}$ or PEF of $>20 \%$ from the baseline two to 12 hours after challenge.

SPECIFIC CHALLENGE TEST WITH WOOD DUST Crude red cedar dust or spruce dust was first placed in an incubator at $60^{\circ} \mathrm{C}$ for 24 hours to dry. The wood dust was sieved through a strainer with a pore size of $0.5 \mathrm{~mm}$. Each

Table 2 Time to maximal drop of FEV and PEFR after inhalation tests with plicatic acid and cedar dust

\begin{tabular}{|c|c|c|c|c|c|}
\hline \multirow{2}{*}{$\begin{array}{l}\text { Subject } \\
\text { No }\end{array}$} & \multirow[b]{2}{*}{ Variables } & \multicolumn{2}{|c|}{ Challenge with plicatic acid } & \multicolumn{2}{|c|}{ Challenge with cedar dust } \\
\hline & & $\%$ Drop & Peak time & $\%$ Drop & Peak time \\
\hline 1: & FEV, & $<5$ & $30 \mathrm{~min}$ & $<5$ & $10 \mathrm{~min}$ \\
\hline \multirow{2}{*}{ 2: } & PEFR & $<5$ & $18 \mathrm{~h}$ & NA & \\
\hline & FEV & 6 & $40 \mathrm{~min}$ & 14 & $3 \mathrm{~h}$ \\
\hline 3: & $\begin{array}{l}\text { PEFR } \\
\text { FEV }\end{array}$ & 16 & $7 \mathrm{~h}$ & 5 & $7 \mathrm{~h}$ \\
\hline \multirow{3}{*}{ 4: } & PEFR & $\begin{array}{l}14 \\
15\end{array}$ & $50 \mathrm{~min}$ & 6 & $50 \mathrm{~min}$ \\
\hline & $\mathrm{FEV}_{1}$ & $<5$ & $2 \mathrm{~h}$ & 5 & $40 \mathrm{~min}$ \\
\hline & PEFR & 21 & $10 \mathrm{~h}$ & 9 & $10 \mathrm{~h}$ \\
\hline 5: & $\mathrm{FEV}_{1}$ & 41 & $7 \mathrm{~h}$ & $<5$ & $5 \mathrm{~h}$ \\
\hline \multirow{2}{*}{ 6: } & PEFR & 23 & $7 \mathrm{~h}$ & 11 & $7 \mathrm{~h}$ \\
\hline & FEV & 27 & $30 \mathrm{~min}$ & 5 & $10 \mathrm{~min}$ \\
\hline \multirow{2}{*}{ 7: } & PEFR & 34 & $8 \mathrm{~h}$ & 10 & $20 \mathrm{~min}$ \\
\hline & FEV $_{i}$ & 32 & $40 \mathrm{~min}$ & 38 & $10 \mathrm{~min}$ \\
\hline \multirow{2}{*}{ 8: } & PEFR & 18 & $40 \mathrm{~min}$ & 30 & $20 \mathrm{~min}$ \\
\hline & FEV $_{1}$ & 16 & $50 \mathrm{~min}$ & 8 & $60 \mathrm{~min}$ \\
\hline \multirow{2}{*}{ 9: } & PEFR & 58 & $8 \mathrm{~h}$ & 43 & $12 \mathrm{~h}$ \\
\hline & FEV & $<5$ & $40 \mathrm{~min}$ & $<5$ & $20 \min$ \\
\hline & PEFR & 23 & $12 \mathrm{~h}$ & 25 & $11 \mathrm{~h}$ \\
\hline
\end{tabular}

sample was examined under the microscope. The particles that belonged to each of the following categories $<10 \mu \mathrm{m}, 10-50 \mu \mathrm{m}$, and $>50 \mu \mathrm{m}$ were counted in each field of a counting chamber used to count white cells. A total of 20 fields was examined for each sample. For cedar dust, the distribution of particle size was $54 \%(<10 \mu \mathrm{m}), 18 \%(10-50 \mu \mathrm{m})$, and $28 \%(>50 \mu \mathrm{m})$. The corresponding figures for spruce dust were $59 \%, 18 \%$, and $23 \%$.

The wood dust was then placed in a rotahaler (Allen and Hanburys, Toronto, Montreal) directly in doses of $20 \mathrm{mg}$ or $40 \mathrm{mg}$, depending on the $\mathrm{PC}_{20}$ of the patient. The rotahaler was placed in a horizontal position all the time to avoid spilling the dust. Patients were asked to inhale from functional residual capacity to total lung capacity and to hold their breath for 10 seconds after inhalation. The $\mathrm{FEV}_{1}$ was measured every $10 \mathrm{~min}$ utes after inhalation for the first hour. If the $\mathrm{FEV}_{\text {, }}$ fell by $<20 \%$ from the baseline during the first hour, another dose of red cedar dust was given by inhalation until a total dose of $80 \mathrm{mg}$ had been given. On another day, $80 \mathrm{mg}$ of fine spruce dust was given in the same manner as the red cedar dust through the rotahaler as a control dust test. Lung function tests were determined after a challenge with wood dust in the same manner as the challenge with plicatic acid.

This study was approved by the Ethics Committee of the University of British Columbia.

\section{Results}

Table 1 shows the characteristics of the nine male patients. Their median (range) age was 34 (24 to 60) years. Four of the nine patients had positive immediate skin reactions to one or more of the 25 common allergens on the prick test. Two patients (Nos 6 and 8) presented with abnormal baseline lung function. One showed an abnormally low FVC and another showed an obstructive ventilatory defect. Two patients had normal bronchial responsiveness $\left(\mathrm{PC}_{20}>32 \mathrm{mg} / \mathrm{ml}\right)$ before a challenge test with plicatic acid.

Table 2 presents the time and extent of maximal change in pulmonary function after challenge tests. Of the nine patients, six developed a positive reaction to a challenge test with plicatic acid. One (No 7) had an isolated immediate asthmatic reaction, four had isolated late reactions, and the remaining one 
No 6) had a dual reaction. Of the six patients who reacted to plicatic acid, only three (Nos 7,8 , and 9) reacted to challenge with red cedar dust delivered by the rotahaler. One (No 7) developed an isolated immediate asthmatic reaction 20 minutes after challenge and the remaining two (Nos 8 and 9) had isolated late reactions at 11 and 12 hours after challenge similar to the type of reaction developed after challenge with plicatic acid. The three patients (Nos 4, 5, and 6) who showed a positive reaction to plicatic acid challenge but did not have a positive reaction to challenge with red cedar dust, had a maximal drop in lung function from $9 \%$ to $11 \%$ after challenge with red cedar dust. The remaining three patients with negative reactions to challenge with plicatic acid also had a negative reaction to challenge with red cedar dust. None of the patients reacted to challenge with spruce dust.

\section{Discussion}

Specific challenge tests, when performed properly, are considered to be standard tests for confirming the diagnosis of occupational asthma. Occupational challenge tests with allergenic dust have been performed by a simple method described by Pepys and Hutchcroft. ${ }^{1}$ This method involves pouring the dust repeatedly from one tray to another placed $30 \mathrm{~cm}$ below for varying periods of time. It requires an enclosed chamber to prevent laboratory personnel from being sensitised. After challenge, the chamber needs to be cleaned up; thus technical staff are exposed to the dust. Also, it is difficult to adjust the dose of exposure except by adjustment of the duration of exposure. Cloutier et al reported a new device to deliver powders, which consisted of a particle generator, an aerosol delivery system, and monitors. ${ }^{4}$ The particle size and concentration of dust were monitored during the test. Although this equipment has circumvented the disadvantages of the old exposure method, it requires special technical support and is not freely available to most hospitals and clinics.

The use of a spinhaler to deliver micronised freeze dried common allergen powder was first reported in 1982.12 Godnic-Cvar and Gomzi applied this method of delivery to confirm the diagnosis of occupational asthma. ${ }^{13}$ The authors used the spinhaler to deliver 40 $\mathrm{mg}$ of palisander wood dust in a capsule to a patient who developed a specific reaction to this wood dust by this method of challenge.

The rotahaler is a flow activated device and has been used in the treatment of asthma and chronic obstructive lung disease for a long time. Orgel et al showed that all 40 patients in their series could empty a rotahaler with a single inhalation. ${ }^{14} \mathrm{We}$ selected the rotahaler because wood dust could be placed directly in the space of the device rather than into capsules. With this method, there was no false positive reaction compared with challenge with plicatic acid. The sensitivity was low, however, as only three out of six patients who had a positive reaction to plicatic acid reacted to the dust challenge, the remaining three patients had a fall in FEV, and a PEF of $<20 \%$ from the baseline. One reason for the low sensitivity could be the dose of wood dust given. Only $50 \%$ of wood dust particles were $<10 \mu \mathrm{m}$ in diameter and therefore inhalable. Moreover, it is likely that only a small proportion of the inhaled dust reached the lower airways. Vidgren et al reported that only $9 \%$ of disodium cromoglycate labelled with ${ }^{99 \mathrm{~m}} \mathrm{Tc}$ delivered by rotahaler was deposited in the lung. ${ }^{15}$ We did not give more than $80 \mathrm{mg}$ of wood dust as we did not know the content of plicatic acid in the wood dust. At present we do not have a simple method to measure the amount of plicatic acid in the wood dust. This method of challenge needs further refinement such as the use of only particles of wood dust $<10 \mu \mathrm{m}$ in diameter and determination of the content of plicatic acid in the sample. Because of the small sample size of our patients, it is too early to suggest that this method can replace the challenge with plicatic acid in the diagnosis of red cedar asthma.

In conclusion, we presented a simple method of delivering wood dust by a rotahaler for occupational challenge tests. It has the merits of being cheap, easy to use, and practical. Our pilot study showed that a positive response to challenge with red cedar dust with the rotahaler was diagnostic for red cedar asthma but a negative test cannot rule out the diagnosis. The use of a rotahaler to deliver allergic dust for occupational challenge tests deserves further evaluation.

1 Chan-Yeung M, Lam S. Occupational asthma. Am Rer Respir Dis 1986;133:686-703.

2 Blanc P. Occupational asthma in a national disability survey. Chest 1987;92:613-7.

3 Marabini A, Dimich-Ward H, Kwan SYL, Kennedy SM Waxler-Morrison $M$, Chan-Yeung $M$. Clinical an socio-economic features of subjects with red cedar asthma: a follow-up study. Chest 1993;104:821-4

4 Cloutier Y, Lagier F, Lemieux R, et al. New methodolog for specific inhalation challenges with occupationa agents in powder form. Eur Respir $₹$ 1989;2:769-77.

5 Chan-Yeung M, Barton G, MacLean L, Grzybowski S. Occupational asthma and rhinitis due to western red cedar (Thuya plicata). Am Rev Respir Dis 1973;108: 1094-102.

6 Chan-Yeung M. Western red cedar and other wood dusts. In: Bernstein IL, Chan-Yeung M, Malo J-L, Bernstein DI, ed. Asthma in the workplace. New York: Marcel

7 Cartier A, Malo JL. Occupational challenge tests. In: Bernstein IL, Chan-Yeung M, Malo J-L, Bernstein DI ed. Asthma in the workplace. New York: Marcel Dekker 1993:227.

8 Crapo RO, Morris AH, Gardner RM. Reference spirometric values using techniques and equipment that meet ATS recommendations. Am Rev Respir Dis 1981;123 659-64.

9 Cockcroft D, Killian D, Mellon J, Hargreave F. Bronchial reactivity to inhaled histamine: a method and clinical survey. Clinical Allergy 1977;7:235-43.

10 Chan-Yeung M, MacLean L, Paggiaro P. Follow up study of 232 patients with occupational asthma caused by of 232 patients with occupational asthma caused by 1987;79:792-6.

11 Pepys J, Hutchcroft BJ. Bronchial provocation tests in etiologic diagnosis and analysis of asthma. Am Rev Respir Dis 1975;112:829-59.

12 Boner AL, Vallone G, Bennati D, Falagiani P, Gaburro D. Simplified spinhaler method for antigen-specific bronchoprovocation in children with bronchial asthma. I. Ann Allergy 1986;57:363-6.

13 Godnic-Cvar J, Gomzi M. Case report of occupational asthma due to palisander wood dust and bronchoprovocation challenge by inhalation of pure wood dust from capsule. Am f Ind Med 1990;18:541-5.

14 Orgel H, Meltzer E, Welch M, Kemp J. Inhaled albuterol powder for the treatment of asthma-a dose-response study. I Allergy Clin Immunol 1985;75:468-71.

15 Vidgren $M$, Paronen $P$, Vidgren P, Vainio P, Nuutinen J. In vivo evaluation of the new multiple dose powder inhaler and the Rotahaler using the gamma scintigraphy. Acta Pharmaceutica Nordica 1990;2:3-10. 